\title{
Middle and proximal sections of the human internal mammary artery are not "passive conduits"
}

Recent studies have shown that blood flow through the internal mammary artery graft is inadequate for maximal exercise and that hypoperfusion may be worsened by high-dose vasopressor therapy that could further reduce arterial graft flow. Histologic studies have suggested that the human internal mammary artery is an elastic "passive conduit" along the majority of its length. However, although the pharmacologic reactivity at the distal section of the internal mammary artery has been extensively studied, this evaluation has never been done at the middle and proximal sections. It is extremely important to understand the contractility at the midsection of the internal mammary artery because, in a critical situation, any contraction may further reduce the internal mammary artery flow. The present study was designed to investigate the following: (1) Is it true that the pharmacologic reactivity of the human internal mammary artery is different among various sections? and (2) Is the human internal mammary artery a nonreactive "passive conduit" at its most important area used as the graft-the middle and the proximal sections? One hundred six human internal mammary artery ring segments taken from patients who underwent internal mammary artery grafting procedures ( 29 from the proximal, 38 from the middle, and 39 from the distal sections) were studied in the organ bath under a physiologic pressure. Concentration-response curves were established for norepinephrine, endothelin-1, U46619, potassium, and glyceryl trinitrate (precontracted with $10 \mathrm{nmol} / \mathrm{L}$ U46619). Contraction forces were standardized (in grams per millimeter circumference) at a pressure of $100 \mathrm{~mm} \mathrm{Hg}$. The contraction force was greater in the distal section than in other sections for norepinephrine $(p=0.002)$ and endothelin-1 $(p=0.04)$. No differences were seen for potassium, U46619, or glyceryl trinitrate, whereas the effective concentration inducing $50 \%$ of maximal response for $\mathrm{U} 46619$ was 100 -fold lower in the distal than in the middle section $(9.06 \pm 0.34$ versus $7.06 \pm 0.48-\log \mathrm{M} ; p=0.01)$ indicating higher sensitivity in the distal section. This study for the first time shows various reactivity along the full length of the human internal mammary artery and shows that the distal section is the most reactive part of the graft. However, although the middle and the proximal sections are less reactive to some vasoconstrictors (norepinephrine and endothelin-1), it is not a "passive conduit" and it contracts with all four vasoconstrictors tested. The contractility at the midsection should be fully appreciated because, under critical postoperative situations (hypoperfusion) or during exercise with marginal flow, the ability of these sections to contract in response to vasoconstrictors may become clinically detrimental and require pharmacologic therapy. (J ThORAC CARDIOvaSC SURG 1994;108: 741-6)

Guo-Wei He, MD, PhD, ${ }^{\mathrm{a}, \mathrm{b}}$ Tea E. Acuff, MD, ${ }^{\mathrm{b}}$ Cheng-Qin Yang, MD ${ }^{\mathrm{a}, \mathrm{b}}$

William H. Ryan, MD, ${ }^{\mathrm{b}}$ and Michael J. Mack, MD, ${ }^{\mathrm{b}}$ Portland, Ore., and Dallas, Tex.

From the Albert Starr Academic Center for Cardiac Surgery, ${ }^{\text {a }}$ St. Vincent Heart Institute, Portland, Ore., and Cardiothoracic Surgery Associates of North Texas at Medical City Dallas Hospital, Dallas, Tex. $^{b}$

Received for publication Dec. 23, 1993.

Accepted for publication May 2, 1994.
Address for reprints: Guo-Wei He, MD, PhD, Director, Cardiovascular Research, the Albert Starr Academic Center for Cardiac Surgery, St. Vincent Heart Institute, Suite 240, 9155, Barnes Rd., Portland, OR 97225.

Copyright ${ }^{\circledR} 1994$ by Mosby-Year Book, Inc.

$0022-5223 / 94 \$ 3.00+0 \quad \mathbf{1 2} / \mathbf{1} / \mathbf{5 7 1 6 9}$ 
Although superior long-term patency rates of internal mammary artery (IMA) grafting have led to the extensive use of this arterial graft, ${ }^{1-3}$ recent studies have shown that blood flow through arterial grafts (IMA grafts were used in most of the patients) is inadequate for maximal exercise ${ }^{4}$; it was also shown that inadequate graft flow may cause a hypoperfusion syndrome manifested by low cardiac output, left ventricular failure, rising pulmonary wedge pressure, hypotension, and cardiac arrest. ${ }^{5}$ Severe hypoperfusion tends to occur early in the patient's course, and this situation may be worsened by high-dose vasopressor therapy that could further reduce arterial graft flow. ${ }^{5,6}$ Histologic studies ${ }^{7,8}$ have suggested that the human IMA is an elastic "passive conduit" along most of its length. On the basis of the histologic observations and pharmacologic studies, a hypothesis that the human IMA is an artery with different reactivity along its length has been proposed. ${ }^{9}$ This hypothesis suggests that, at the midsection, the IMA is basically a "passive conduit," whereas it is pharmacologically reactive at the distal and the proximal sections. However, although the pharmacologic reactivity at the distal section of the IMA has been extensively studied, ${ }^{9-17}$ this analysis has never been done at the proximal and middle sections. Therefore, two questions must be answered: (1) Is it true that the pharmacologic reactivity of the human IMA is different among various sections? and (2) Is the human IMA a nonreactive "passive conduit" at its most important area used as the graft-the middle and the proximal sections? The characteristics of the IMA are extremely important in a critical situation because any contraction may further reduce the IMA flow. The present study was designed to answer these questions.

\section{Methods}

Segments of the human IMA (either left or right) were nonselectively collected from patients undergoing IMA grafting procedures whenever available. These segments were taken from either the distal section, the proximal section (usually when a free IMA graft is used), or the midsection when an extremely short length of an IMA graft was needed or when an IMA was considered inadequate to use as a graft because of low flow measured from the free distal end. The midsection was defined in the present study as at least $4 \mathrm{~cm}$ from the distal bifurcation or $4 \mathrm{~cm}$ from the origin of the IMA from the subclavian artery. This definition was created for two reasons. First, by this definition, the length of the midportion of IMA is about $60 \%$ of the total length $(19.5 \pm 2.4 \mathrm{~cm})$ and contains more elestic lamellae than do the proximal and the distal portions. ${ }^{7}$ Second, even used as a "free graft," this portion of IMA is almost always essential and therefore is the most important part as a graft. Approval to use discarded IMA tissue was given by the Human Ethics Committee of the Medical City Dallas Hospital. After sternotomy, full-length left IMA pedicle was carefully dissected from the chest wall. The patients were then heparinized, and cardiopulmonary bypass was instituted. The left IMA was cut distally, and the length for grafting to the left anterior descending artery was carefully measured and preserved. Any discarded distal IMA segments were collected and put in a container with oxygenated physiologic solution (Krebs), maintained at $4^{\circ} \mathrm{C}$, and then transferred to the laboratory immediately. The IMA was transferred into a glass dish and dissected out from its surrounding connective tissue. The IMA was then cut into 3 mm-long rings, which were then suspended on wires in organ baths. ${ }^{10,11}$ The Krebs solution had the following composition (in millimoles per liter): $\mathrm{Na}^{+} 144, \mathrm{~K}^{+} 5.9, \mathrm{Ca}^{2+} 2.5, \mathrm{Mg}^{2+} 1.2, \mathrm{Cl}^{-}$ $128.7, \mathrm{HCO}_{3}{ }^{-} 25, \mathrm{SO}_{4}{ }^{2-} 1.2, \mathrm{H}_{2} \mathrm{PO}_{4}{ }^{-1} 1.2$, and glucose 11 . The solution was aerated with a gas mixture of $95 \% \mathrm{O}_{2}-5 \% \mathrm{CO}_{2}$ at $37 \pm 0.1^{\circ} \mathrm{C}$

Organ bath technique. A technique that allowed vascular rings to be normalized under a physiologic pressure in vitro, by establishing the individual length-tension curve for each vascular segment, was used to set the vascular rings at a pressure comparable with that at the in vivo situation. The details of the technique have been previously published. ${ }^{11}{ }^{18}$ Because of the importance of vascular endothelium in modulating contraction or relaxation, we intentionally preserved the endothelium by cautiously dissecting and mounting the rings. ${ }^{13,18}$

Protocol. After the normalization procedure, the IMA rings were equilibrated for 1 hour. The following protocols were designed for the experiments.

Contraction. Diameters of the IMA at a pressure of $100 \mathrm{~mm}$ $\mathrm{Hg}$ (D100) were recorded from the normalization procedure. The cumulative concentration-contraction curve was established for the following vasoconstrictor substances: endothelin-1 (ET), norepinephrine (NE), U46619 (a stable thromboxane $A_{2}$ mimetic), and the membrane-depolarizing agent potassium chloride $\left(\mathrm{K}^{+}\right)$. The total contraction force and the standardized force $(\mathrm{Fn})$ were used to compare the contraction among the different sections. As previously described, ${ }^{9}$ the standardized contraction force was calculated by the following equation: $\mathrm{Fn}=$ Force (grams) $/ \mathrm{C}_{100}$ (millimeters), where $\mathrm{C}_{100}$ is the circumference at a pressure of $100 \mathrm{~mm} \mathrm{Hg}$ and $\mathrm{C}_{100}=\pi \times \mathrm{D}_{100}$. The meaning of Fn is the force (grams) produced by $1 \mathrm{~mm}$ of circumference of the vessel. Because the length of the IMA rings is equal $(3 \mathrm{~mm})$, the Fn represents the force produced by each millimeter of the circumference at a length of $3 \mathrm{~mm}$. Therefore, comparison of Fn among arteries with different diameters is more logical in regard to test contractility.

Relaxation. The maximal relaxation induced by glyceryl trinitrate on U46619 (10 nmol/L)-induced contraction was analyzed as percentage relaxation of the precontraction. $\mathrm{EC}_{50}$ : Sensitivity of the IMA to vasoconstrictor (U46619, $\mathrm{K}^{+}, \mathrm{NE}$, and ET) or vasodilator (glyceryl trinitrate) agents is expressed by the effective concentration which induced $50 \%$ of maximal effect (either contraction or relaxation). The $\mathrm{EC}_{50}$ was determined from each concentration-contraction (or relaxation) curve by a logistic, curve-fitting equation ${ }^{19}: E=M A^{p}$ / $\left(A^{p}+K^{p}\right)$ where $E$ is response, $M$ is maximal contraction (or relaxation), $A$ is concentration, $K$ is $E_{50}$ concentration, and $p$ is the slope parameter.

The similar protocol was used for the rings taken from the proximal, middle, or distal sections of the IMA. Analysis of variance and the Scheffé test (as the post-hoc test) were used to compare the Fn for each vasoconstrictor, the percentage relax- 


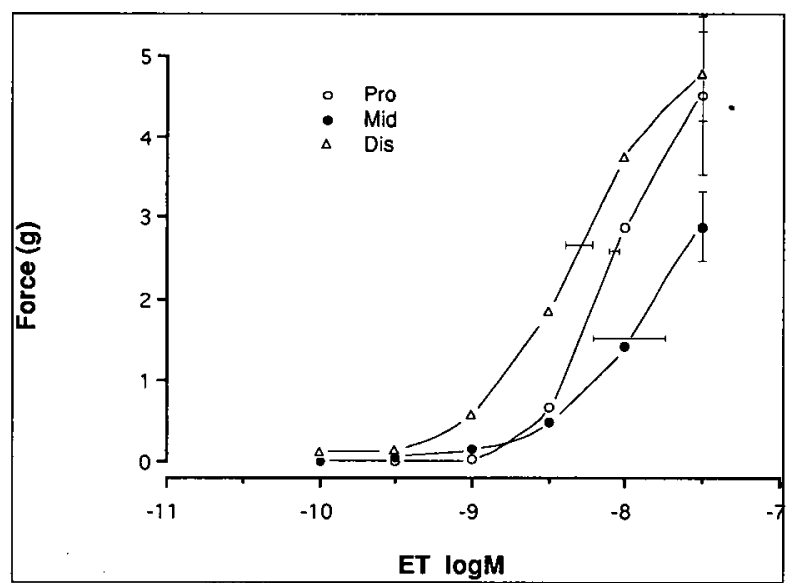

Fig. 2. Mean concentration $(-\log M)-$ contraction curves for endothelin $(E T)$ at the proximal (O Pro, $n=5)$, middle ( $\bullet$ Mid, $n=7)$, and distal ( $\Delta$ Dis, $n=11)$ sections of the IMA. Symbols represent data averaged from a group of IMA rings. Horizontal bars are placed on $\mathrm{EC}_{50}$ values ( \pm 1 standard error of the mean), averaged from logistic, fitted curves from each ring. Vertical bars are 1 standard error of the mean at the maximum response.

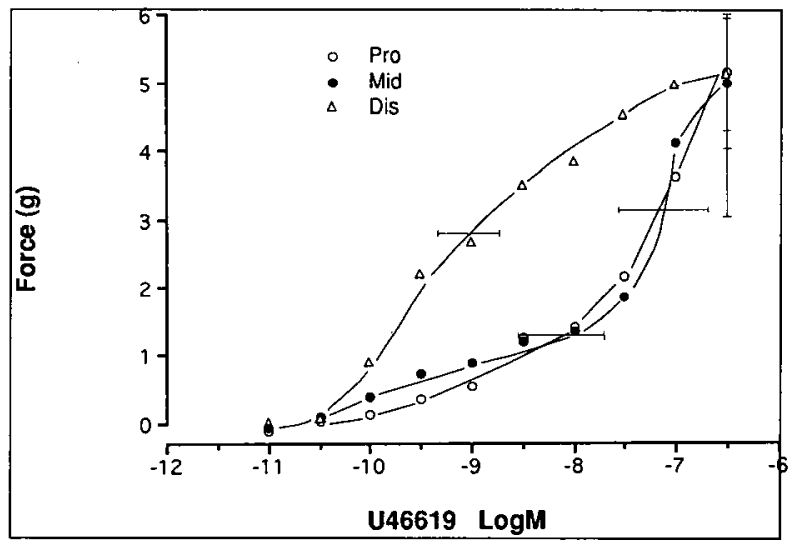

Fig. 3. Mean concentration $(-\log M)-$ contraction (Force, g) curves for U46619 at the proximal (O Pro, $n=6$ ), middle ( Mid, $n=10$ ), and distal ( $\Delta$ Dis, $n=7$ ) sections of the IMA. Symbols represent data averaged from a group of IMA rings. Horizontal bars are placed on $\mathrm{EC}_{50}$ values ( \pm 1 standard error of the mean), averaged from logistic, fitted curves from each ring. Vertical bars are 1 standard error of the mean at the maximum response.

tal section than in the mid section of the IMA $(9.72 \pm$ 0.61 versus $7.06 \pm 0.48-\log \mathrm{M} ; p=0.016$, Scheffé test) indicating a much higher sensitivity to this vasoconstrictor in the distal section than in the midsection of the IMA. No statistical difference was found between the proximal 


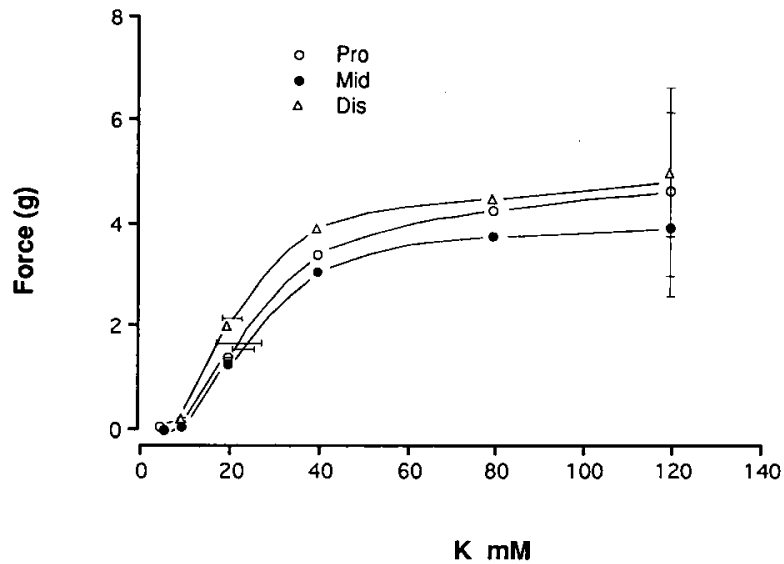

Fig. 4. Mean concentration ( $m M)$ - contraction (force, $g$ ) curves for potassium (K) at the proximal (O Pro, $n=6$ ), middle $(\bullet$ Mid, $n=8)$, and distal $(\Delta D i s, n=7)$ sections of the IMA. Symbols represent data averaged from a group of IMA rings. Horizontal bars are placed on $\mathrm{EC}_{50}$ values $( \pm 1$ standard error of the mean), averaged from logistic, fitted curves from each ring. Vertical bars are 1 standard error of the mean at the maximum response.

and the middle sections with regard to the $\mathrm{Fn}$ or $\mathrm{EC}_{50}$ for the all four vasoconstrictors.

Table II and Figure 5 show the maximum relaxation induced by glyceryl trinitrate in U46619-precontracted rings of the proximal, middle, and distal sections of the IMA. No difference was found either in the maximum relaxation or in the $\mathrm{EC}_{50}$.

\section{Discussion}

In the present study, we were able to, for the first time, show that the reactivity of the human IMA is variable along its full length and that the distal section of this artery has the highest reactivity. We tested four potential spasmogens for the human IMA. Thromboxane $\mathrm{A}_{2}$, represented by its stable analog $U 46619$, is released from platelets and has been shown to be the most potent vasoconstrictor in the human IMA. ${ }^{10,17} \mathrm{ET}$, a vasoconstrictor substance derived from endothelial cells, has been suggested in general as the most powerful vasoconstrictor for blood vessels ${ }^{20,21}$ and measured with an increased release during cardiopulmonary bypass for coronary artery bypass grafting. ${ }^{22} \alpha$-Adrenoceptor agonists are generally considered to be causes of vasospasm, ${ }^{23}$ and the $\alpha_{1}$-adrenoceptor has been shown to be predominant in the human IMA. ${ }^{10,12-14}$ Apart from these receptor stimuli, potassium ion was also chosen because it depolarizes cellular membrane and therefore opens voltage-dependent calcium channels to cause calcium influx and finally con-

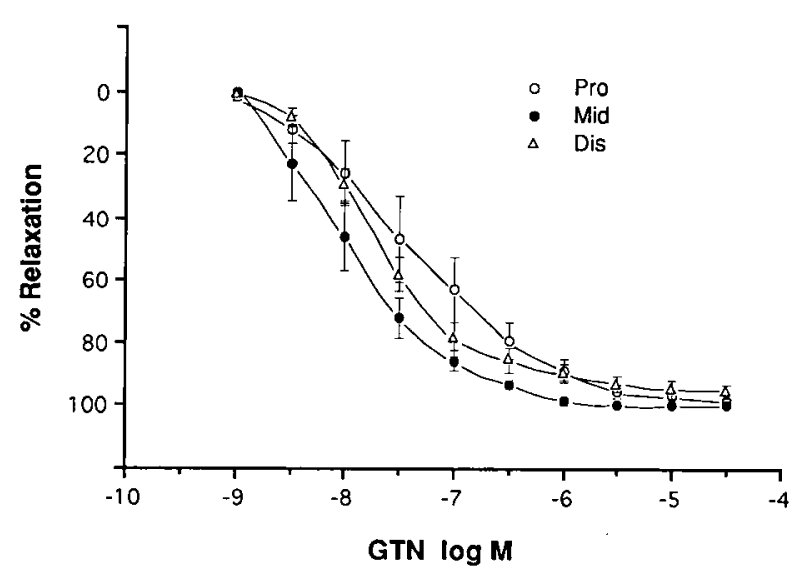

Fig. 5. Mean concentration $(-\log \mathrm{M})-$ relaxation (\% of precontraction) curves for glyceryl trinitrate $(G T N)$ at the proximal (O Pro, $n=6)$, middle $(\bullet \operatorname{Mid}, n=5)$, and distal $(\Delta D i s, n=7)$ section of the IMA. Symbols represent data averaged from a group of IMA rings. The precontraction was induced by $\mathrm{U} 46619(10 \mathrm{nM})$. Vertical bars are 1 standard error of the mean of the response at each concentration.

tract smooth muscle cells. ${ }^{10}$ The present study shows that the distal section is more contractable to two receptor agonists-NE and ET. With regard to thromboxane $\mathrm{A}_{2}$-mediated contraction, although no evidence was found showing that the distal section was more contractable to this receptor agonist, the sensitivity to this vasoconstrictor was higher at this section as indicated by the lower $\mathrm{EC}_{50}$ at this part of IMA. In fact, the $\mathrm{EC}_{50}$ was as much as 100-fold lower in the distal section compared with the midsection, and this disparity represents a much higher sensitivity in this part of the IMA. In general, a contractility is indicated by Fn and sensitivity. A greater contraction force and a higher sensitivity (lower $\mathrm{EC}_{50}$ ) usually mean a greater contractility. Therefore, the present study shows a greater contractility of the distal section compared with that of the middle and proximal sections of IMA. Physiologically, this difference may be important because the distal end of the IMA, possibly the proximal portion as well, regulates blood flow in this artery and thus may shut down when other parts of the body, particularly vital organs, need better perfusion.

On the other hand, the middle and proximal sections of the IMA are not completely passive conduits. Although histologic studies have suggested that the human IMA is a passive conduit, ${ }^{7,8}$ on the basis of the fact that this artery contains more elastic lamellae than other arteries, such an artery is not necessarily a completely passive conduit because there are still smooth muscle cells in the arterial 
Table I. Comparison of standardized contraction force and $E C_{50}$ for four vasoconstrictors between various sections of the human IMA

\begin{tabular}{|c|c|c|c|c|c|c|c|c|}
\hline \multirow[b]{2}{*}{ Agents } & \multicolumn{4}{|c|}{$F n$} & \multicolumn{4}{|c|}{$E C_{50}(-\log M)$} \\
\hline & Proximal & Middle & Distal & $\overline{\mathrm{p} \text { Value }}$ & Proximal & Middle & Distal & $\mathrm{p}$ Value \\
\hline $\mathrm{NE}$ & $\begin{array}{c}0.29 \pm 0.08^{*} \\
(\mathrm{n}=6)\end{array}$ & $\begin{array}{c}0.25 \pm 0.07^{*} \\
(\mathrm{n}=8)\end{array}$ & $\begin{array}{l}0.73 \pm 0.11 \\
(\mathrm{n}=7)\end{array}$ & 0.002 & $6.25 \pm 0.27$ & $6.19 \pm 0.17$ & $5.91 \pm 0.16$ & 0.42 \\
\hline ET & $\begin{array}{c}0.59 \pm 0.3 \\
(n=5)\end{array}$ & $\begin{array}{c}0.44 \pm 0.08^{*} \\
(\mathrm{n}=7)\end{array}$ & $\begin{array}{c}0.74 \pm 0.06 \\
(\mathrm{n}=11)\end{array}$ & 0.04 & $8.11 \pm 0.04$ & $7.92 \pm 0.24$ & $8.31 \pm 0.07$ & 0.14 \\
\hline U46619 & $\begin{array}{c}0.45 \pm 0.15 \\
(n=6)\end{array}$ & $\begin{array}{c}0.8 \pm 0.17 \\
(n=10)\end{array}$ & $\begin{array}{l}0.95 \pm 0.14 \\
(n=7)\end{array}$ & 0.16 & $8.15 \pm 0.44$ & $7.06 \pm 0.48^{*}$ & $9.06 \pm 0.34$ & 0.01 \\
\hline $\mathrm{K}^{+}$ & $\begin{array}{c}0.45 \pm 0.17 \\
(\mathrm{n}=6)\end{array}$ & $\begin{array}{c}0.65 \pm 0.17 \\
(n=8)\end{array}$ & $\begin{array}{c}0.84 \pm 0.13 \\
(n=7)\end{array}$ & 0.28 & $21.27 \pm 5.35 \dagger$ & $22.51 \pm 2.57 \dagger$ & $20.94 \pm 1.99 \dagger$ & 0.94 \\
\hline
\end{tabular}

$F n$, Contraction force (in grams) standardized by circumference at a pressure of $100 \mathrm{~mm} \mathrm{Hg}$

${ }^{*} p<0.05$ in comparison to the distal section (Scheffé test).

$+\mathrm{EC}_{50}$ for $\mathrm{K}^{+}$in millimoles per liter.

Table II. Relaxation induced by glyceryl trinitrate

\begin{tabular}{|c|c|c|c|c|c|c|c|c|}
\hline & \multicolumn{4}{|c|}{ Maximum relaxation (\%) } & \multicolumn{4}{|c|}{$E C_{50}$} \\
\hline & Proximal & Middle & Distal & $\overline{\mathrm{p} \text { Value }}$ & Proximal & Middle & Distal & $\mathrm{p}$ Value \\
\hline Glyceryl trinitrate & $\begin{array}{c}98.45 \pm 1.09 \\
(n=6)\end{array}$ & $\begin{array}{c}100 \\
(n=5)\end{array}$ & $\begin{array}{c}95.54 \pm 2.21 \\
(n=7)\end{array}$ & 0.18 & $7.40 \pm 0.22$ & $7.99 \pm 0.18$ & $7.73 \pm 0.09$ & 0.08 \\
\hline
\end{tabular}

The maximal relaxation is expressed as percentage of precontraction induced by $\mathrm{U} 46619(10 \mathrm{nmol} / \mathrm{L}), n$, Number of ring segments.

wall. Previous pharmacologic studies have shown that the human IMA at the distal section is a pharmacologically reactive artery, ${ }^{9-17}$ which is in accordance with clinical reports. ${ }^{24,25} \mathrm{~A}$ recent histologic study is in accordance with our pharmacologic studies. ${ }^{26} \mathrm{~A}$ clinical trial on the pharmacologic dilatation of the IMA during surgical procedures has shown that the IMA flow significantly increases when intraluminal injection of pharmacologic agents is used, ${ }^{27}$ and our present study is in accordance with the clinical trial. From the present study, the midsection of the IMA contracts with all four vasoconstrictors tested to a certain extent, which suggests that even this part of the IMA is still a reactive conduit despite the fact that there are fewer smooth muscle cells at the midsection than at other sections. Alternative evidence, implicating the reactive characteristic of the middle and the proximal sections of the IMA, is that these two sections react to vasoconstrictor thromboxane $\mathrm{A}_{2}$ (U46619) and $\mathrm{K}^{+}$to the same extent as does the distal section (Table I). Because the reactivity (to NE and ET) of the middle and proximal sections is significantly less than that of the distal section and, also, because these sections are significantly larger in diameter than the distal section, vasospasm is usually more frequently encountered in the smaller and more reactive distal end rather than in the middle and the proximal sections of the IMA. However, the contractility at the middle and proximal sections needs to be fully appreciated because the contraction at these sections in response to vasoconstrictors may reduce the diameter and the flow in the IMA graft and therefore produce detrimental effects. Under a marginal situation, such as postoperative hypoperfusion, this factor may be critical.

In this study, we did not detect any difference among the different sections with regard to the relaxation induced by glyceryl trinitrate. This finding may imply that the difference along the full length of IMA only involves the contractile but not the relaxing property.

In summary, the present study has shown for the first time that the distal section of the human IMA has the greatest contractility compared with the middle and proximal sections. This finding suggests that the distal section of the IMA is the part where vasospasm may develop and requires the greatest care. However, although the middle and the proximal sections are less pharmacologically reactive than the distal section to some vasoconstrictors, these sections are not completely nonreactive passive conduits because they contract with various vasoconstrictors. This finding may have important postoperative implications. In particular, under critical postoperative situations (hypoperfusion) or during exercise with marginal flow, the ability of these sections to contract in response to vasoconstrictors may become clinically detrimental and require pharmacologic therapy. 
We are grateful to Drs. David Moore and Jose Vidal for their active support in providing the IMA tissue and to Christine Scheitlin, RN, and Carol Nicholson, RN, MS, for their technical assistance.

\section{REFERENCES}

1. Loop FD, Lytle BW, Cosgrove DM, et al. Influence of the internal-mammary-artery graft on 10-year survival and other cardiac events. N Engl J Med 1986;314:1-6.

2. Barner HB, Standeven JW, Reese J. Twelve-year experience with internal mammary artery for coronary artery bypass. J THORAC CARdiovasc SuRG 1985;90:668-75.

3. Kirklin JW, Akins CW, Blackstone EH, et al. ACC/AHA guidelines and indications for coronary artery bypass graft surgery. Circulation 1991;83:1125-73.

4. Kawasuji M, Tedoriya T, Takemura H, Sakakibara N, Taki J, Watanabe Y. Flow capacities of arterial grafts for coronary artery bypass grafting. Ann Thorac Surg 1993; 56:957-62.

5. Loop FD, Thomas JD. Hypoperfusion after arterial bypass grafting. Ann Thorac Surg 1993;56:812-3.

6. Jett GK, Arcidi JM Jr, Dorsey LMA, Hatcher CR Jr, Guyton RA. Vasoactive drug effects on blood flow in internal mammary artery and saphenous vein grafts. J THORAC Cardiovasc Surg 1987;94:2-11.

7. van Son JAM, Smedts F, de Wilde PCM, et al. Histological study of the internal mammary artery with emphasis on its suitability as a coronary artery bypass graft. Ann Thorac Surg 1993;55:106-13.

8. van Son JAM, Smedts F, Vincent JG, van Lier HJJ, Kubat $\mathrm{K}$. Comparative anatomic studies of various arterial conduits for myocardial revascularization. J THORAC CARDIOVASC SURG 1990;99:703-7.

9. He G-W. Contractility of the human internal mammary artery at the distal section increases toward the end. emphasis on not using the end of the IMA for grafting. $J$ Thorac Cardiovasc Surg 1993;106:406-11.

10. He G-W, Buxton B, Rosenfeldt F, Angus JA. Reactivity of human isolated internal mammary artery to constrictor and dilator agents. implications for treatment of internal mammary artery spasm. Circulation 1989;80(Suppl):I141-50.

11. He G-W, Buxton B, Rosenfeldt F, Wilson AC, Angus JA. Weak $\beta$-adrenoceptor-mediated relaxation in the human internal mammary artery. J THORAC CARDIOVASC SURG 1989;97:259-66.

12. He G-W, Shaw J, Yang C-Q, et al. Inhibitory effects of glyceryl trinitrate on $\alpha$-adrenoceptor mediated contraction in the internal mammary artery. $\mathrm{Br} \mathrm{J}$ Clin Pharmacol 1992; 34:236-43.
13. He G-W, Shaw J, Hughes CF, et al. Predominant $\alpha_{1}$-adrenoceptor mediated contraction in the human internal mammary artery. J Cardiovasc Pharmacol 1993; 21:256-63.

14. He G-W, Acuff TE, Ryan WH, et al. Inhibitory effects of calcium antagonists on $\alpha$-adrenoceptor mediated contraction in the internal mammary artery. $\mathrm{Br} \mathrm{J}$ Clin Pharmac 1994;37:173-9.

15. Jett GK, Guyton RA, Hatcher CR, Abel PW. Inhibition of human internal mammary artery contractions: an in vitro study of vasodilators. J ThORAC Cardiovasc Surg 1992;104:977-82.

16. Schoeffter P, Dion R, Godfraind T. Modulatory role of the vascular endothelium in the contractility of human isolated internal mammary artery. Br J Pharmacol 1988;95:531-43.

17. He G-W.Spasm of internal mammary artery: Is it a secret? J Thorac Cardiovasc Surg 1993;106:381-2.

18. He G-W, Angus JA, Rosenfeldt FL. Reactivity of the canine isolated internal mammary artery, saphenous vein, and coronary artery to constrictor and dilator substances: Relevance to coronary bypass graft surgery. J Cardiovasc Pharmacol 1988;12:12-22.

19. Nakashima A, Angus JA, Jonston CI. Comparison of angiotensin converting enzyme inhibitors captopril and MK421-diacid in guinea pig atria. Eur $\mathrm{J}$ Pharmacol 1982;81:487-92

20. Yanagisawa $\mathbf{M}$, Kurihara $H$, Kimura $S$, et al. A novel potent vasoconstrictor peptide produced by vascular endothelial cells. Nature 1988;332:411-5.

21. Masaki T. Tissue specificity of the endothelin-induced responses. J Cardiovasc Pharmacol 1911;17(Supp! 7):S1-4

22. Van Zwienen JCW, Van der Linden CJ, Cimbrere JSF, Lacquet LK, Booij LHDJ, Hendriks T. Endothelin release during coronary artery bypass grafting [Abstract]. Chest 1993;103:176s.

23. Heusch G. $\alpha$-adrenergic mechanisms in myocardial ischemia. Circulation 1990;81:1-13.

24. Sarabu MR, McClung JA, Fass A, Reed GR. Early postoperative spasm in left internal mammary artery bypass grafts. Ann Thorac Surg 1987;44:199-200.

25. Houghton JL, Callaghan WE, Frank MJ. Disappearance of high-grade left anterior descending stenosis after revascularization. Cathet Cardiovasc Diagn 1988;14:169-71.

26. van Son JAM, Smedts F. Bifurcated ("Y") internal thoracic-coronary artery grafts [Letter]. J THORAC CARDIOVASC SURG 1993;106:945-6.

27. He G-W, Buxton B, Rosenfeldt F, Angus JA, Tatoulis J. Pharmacologic dilatation of the internal mammary artery during coronary bypass surgery. J THORAC CARDIOvASC SURG 1994;107:1440-4. 